\title{
TRANSFORMACIONES Y USOS DEL AGUA EN CALI DURANTE ELPERIODO COLONIAL Y REPUBLICANO ESTUDIO DE CASO: EL RÍO CALI
}

\section{Transformations and uses of water in Cali during colonial and republican period. Case study: Cali River}

\author{
ELIZABETH PATIÑO 1 \\ ${ }^{1}$ Asociación Centro de Estudios Regionales REGION. \\ Departamento de Historia, Universidad del Valle.
}

E-mail: lizabeth000@gmail.com

Recibido: 26 de Septiembre de 2011

Aceptado: 24 de Enero de 2012

\section{Resumen}

El presente artículo es fruto de la investigación que, tomando como punto de referencia los usos del recurso vital: El AGUA, se llevó a cabo para lograr un proceso de contextualización histórica de la ciudad de Santiago de Cali, en el marco del imaginario social y cultural de la sociedad caleña del período Colonial y Republicano. El objetivo principal es contribuir a vincular los estudios históricos con el estudio e investigación de la problemática ambiental; para ello, se ha analizado la importancia del río como fuente de consumo para la subsistencia de la población, seguido de la descripción de los tipos de usos dados al agua (doméstico, económico y lúdico) y del control que se hizo del cauce durante los períodos estudiados. Se estudia igualmente la relevancia del río como foco de conformación en el proceso de colectividad social dentro de la memoria histórica de la sociedad colonial y su influencia y beneficio en la vida cotidiana de los primeros pobladores; a fin, de indagar sobre la complejidad de la relación e influencia del hombre sobre su medio ambiente (sociedadnaturaleza).

Palabras claves: Historiografía, Medio ambiente, Usos del Agua, Sociedad, Naturaleza, Historia ambiental, Historia de Cali.

\section{Abstract}

This article is the result of research undertaken for a historical contextualization of the city of Santiago de Cali, in the context of the social and cultural imaginary of the Cali society during Colonial and Republican period, taking as reference point the uses of the vital resource: WATER. The main goal is to contribute to link the historical studies to the study and research of environmental problems. For that, the importance of the river as a source of consumption for the population is analyzed followed by the description of the types of uses given to water (domestic, economic and recreational) and of the control of the channel that was made during the studied periods. It also examines the importance of the river as a focus of the process of forming social community within the historical memory of colonial society and its influence and welfare for the daily lives of the first settlers, to inquire about the complexity of the relationship and influence of man on his environment (society and nature).

Keywords: Historiography, Environment, Water Use, Society, Nature, Environmental History, History of Cali. 


\section{INTRODUCCIÓN}

Desde épocas inmemoriales, el proceso de conformación de una sociedad ha estado íntegramente relacionado con el agua como fuente vital para el ser humano. A partir de esta concepción, muchas comunidades han configurado sus asentamientos a las orillas de los ríos, utilizándolos como recurso de abastecimiento para la satisfacción de las necesidades básicas de consumo y comercio; al igual de atribuírseles un significado simbólico estructurante como espacio lúdico, de recreo y laboral.

En el caso de la ciudad de Santiago de Cali, no fue diferente. Los primeros pobladores se ubicaron en la margen derecha del río Cali para un mayor beneficio de las actividades diarias. Lo cual permitió que este afluente fluvial marcara considerablemente la realidad y cotidianidad de la sociedad al transformar el paisaje natural a través de la construcción de una malla urbana diferenciada por la espacialidad en cuanto a la lejanía del llano.

A partir de la perspectiva teórica de la Historiografía ambiental, se tratará de entender y analizar las transformaciones y los fenómenos ocurridos en el espacio físico-biótico y los procesos de adaptación de la sociedad caleña en los diferentes momentos históricos estudiados; teniendo en cuenta para ello, en analizar la información en pro de no perder de vista las dinámicas de uso del río Cali, como fuente recurso natural de aprovechamiento y asentamiento de la comunidad. ${ }^{1}$

\section{ESTUDIO DE CASO: EL RÍO CALI Y SU IMPORTANCIA}

En términos de normatividad con respecto al Río Cali, se encontró que el aumento lento de la población provocaría desbordamientos de gran magnitud, que serían atribuidos a factores naturales (veranos e inviernos intensos) y asentamientos de personas pobres a la orilla de éste; situación que conllevaría a adoptar normas enfocadas a proteger la villa de la fuerza natural del río. El autor Gustavo Arboleda menciona que desde el siglo XVII el Cabildo ejecutó una reglamentación orientada a la construcción de puentes debido a que éste aumentaba peligrosamente el cauce del río:

(...) "el 1 de noviembre de 1674, el alcalde don Juan Lasso de los Arcos y Ríos hizo arreglar la acequia y ponerle varios "puentes" de piedra y un "pasadizo" sobre un

\footnotetext{
${ }^{1}$ Nota: Algunos textos en cursiva a lo largo del artículo corresponden a relatos históricos reales de los habitantes de la época. No se realizó ningún tipo de modificación ortográfica ni gramatical, con el objetivo de preservar su originalidad.
}

zanjón que impedía el paso: aumento una acequia para los pobres de los barrios de la Mano del Negro y la Carnicería y el Monte Calvario" (Arboleda 1956).

Este mismo autor hace referencia en más de seis ocasiones, a las peticiones y órdenes realizadas por los habitantes de la ciudad para desviar el río debido a la amenaza constante a la población y casas colindantes. En octubre de 1739, se reglamentan disposiciones para el control de los desbordamientos del río, viéndose gravemente afectada la ciudad debido a las crecientes generadas por el invierno que era muy "crudo"(Arboleda 1956); de igual modo, un mes después el Procurador General don Francisco Domínguez de Irascos realizó una petición al Cabildo para hacer las obras necesarias mediante las cuales se desviara el río de la ciudad a su madre antigua por amenazar con crecientes, y sólo un año después, el 26 de enero de 1740 el Cabildo promulgó un acta de comisión para que dos personas "inteligentes" hicieran la mudanza del cauce del río(A.H.M.C. Tomo 14. Folio 235v) y quince días más tarde, anunció la orden de continuar con las obras adelantadas para desviar el río, frente a la Ermita con jornaleros y abasto (A.H.M.C. Tomo 14. Folio 244-244v).

De la misma manera, se resalta el recibimiento en la villa del visitador Don Alejo González de Mendoza (A.H.M.C. Acta de recibimiento. Tomo 15. Folio 26-27), cuya visita motivó el arreglo de los pasos malos hasta Jamundí y los puentes de esta vía; así mismo, se aprovechó su estancia en la ciudad para pedirle auxilio por el inminente peligro que representaba el río tanto a la Iglesia como a las casas cercanas a ella, esta petición fue expuesta por el mayordomo de la cofradía, el 30 de Octubre 1741 donde se anota que:

\section{(...) "Se aprovechó su presencia en Cali para impedir las avenidas del río en el sitio cercano a la Ermita" que está expuesta a ser llevada por el río. Petición del mayordomo de la cofradía José de Salinas y Becerra, para protegerla" (A.H.M.C. Tomo 15. Folio 32. Petición del 2 noviembre de 1741).}

En relación a esta petición el 2 de Noviembre de 1741, el Señor Gonzáles respondió lo siguiente en relación a dicha petición: "la reunión se efectúa el 6 de Noviembre y se convino en ella echar el río por otra parte en pleno verano" (Arboleda 1956). Particularmente, se encontró que el 12 de Diciembre de 1751, murió Don Francisco Sanjurjo Montenegro, figura representativa de la villa por haber sido designado por el Gobernador de Popayán don José Francisco Carrero el 11 de junio de 1745 como cuidador de la obra de fundación de una casa de recogimiento de mujeres y niñas, al igual que un hospital para enfermos del mal de Lázaro (A.H.M.C. tomo 17. Folio 61). Inclusive, en su oficio público, testó 300 
patacones para desviar el río en las inmediaciones de la Ermita: debido a la amenaza que representaba a la calle contigua a este templo; y otros 300 para construir un PRETIL".

Sin embargo, según Eustaquio Palacios en su obra el Alférez Real esa construcción no fue llevada a cabo:

(...) "ni el río fue desviado ni el pretil fue hecho, aunque hay tradición de que se construyó un muro junto a esa iglesia (La Ermita) para librarla de las fuertes avenidas; $y$ como el tal muro no aparece a la vista, se dice que con el transcurso de los años ha venido a quedar enterrado" (Palacios 1886).

Para 1758, el procurador Diego de Vallecilla mencionó que las crecientes del río amenazaban con destruir la ciudad, a lo cual, el Cabildo acordó que todos los vecinos concurrieran a volver el río a la madre antigua porque se había cargado a la Merced y las crecientes amenazaban con destruir sino toda, parte de la ciudad (ARBOLEDA 1956). No obstante, dos años más tarde el Procurador Yanguas hizo notar el grave daño con el que amenazaba el río a la población, "porque en el Empedrado, el río se había recostado hacia el caserío y las aguas se iban rodando el terreno de una calle que servía de tránsito principal". Hizo notar que nuevamente había el mismo riesgo que en (diciembre) 1761 y (marzo) 1762; afirmando que las reparaciones anteriores habían quedado mal, el Cabildo entonces decidió volver el río a su antiguo lecho (Arboleda 1956).

Aun así, en 1788, el presbítero Don Francisco Antonio Perea, capellán del Cabildo, nuevamente pidió que se reparara el daño con que el río amenazaba a la ciudad y se dispuso a los alcaldes ordinarios para subsanarlo (Arboleda 1956).Seguidamente, en el año de 1792, el 21 de noviembre el procurador solicitó al Cabildo que no se permitiera construir casas en las orillas del río, argumentando que:

(...) "hacía algún tiempo se derramaban con abundancia las aguas de la acequia sobre la calle que por la Merced daba a la salida a las provincias del Chocó y como era mucho el declive volvía al río, cargándose la playa de la Ermita...advertía que en otro tiempo corrían las aguas al margen de esa iglesia y se retiraron de allí a gran costo por el daño que amenazaba, ahora el río volvía a tomar su antiguo curso, quitando al público aquel terreno donde continuamente sale por las tardes a pasear y tomar fresco" (Arboleda 1956), finalizando las obras de desvió en 1794...Obras dirigidas por el alférez Don Manuel de Caicedo quien hizo abrir un hondo cauce llamado desde entonces RIONUEVO y echó por él todo el río; pero éste, más tarde volvió a correr por su santiguo lecho, dejando en el nuevo cauce solo una pequeña porción de sus aguas" (Palacios 1886).

No obstante, aún para inicios del siglo XIX se presentaron varias peticiones mediante las cuales el Consejo Municipal otorgaba permisos y respuestas positivas para la construcción de casas a orillas del río. Entre ellas se pueden destacar las peticiones de Dominga Vivas y Jacoba Escobar vecinas pobres de la ciudad, quienes elevaron una petición a la municipalidad para la construcción de un rancho de piedra valsada y guadua en la tierra de la playa del río; a lo cual el 14 de abril de 1828, la Municipalidad concedió licencia para la construcción, pero dejando en claro que no adquirirían propiedad del terreno (A.H.M.C. Tomo 47. Folio $824-824 v)$.

Igualmente, el Cabildo continuó comisionando y encargando a los regidores del cuidado de las playas del río. Entre las funciones para el cuidado del río estaba la de encañonar las aguas regadas, por el daño que ocasionaban al suelo y evitar que los habitantes sacaran la arena y la tierra por el daño que producían a las vegas del río (A.H.M.C. Tomo 43. Folio 281).

A pesar de las mejoras tomadas a lo largo del siglo XIX, para proteger la ciudad de la fuerza natural del río, en 1893 aún se observaba el afán de los pobladores por defender al pequeño poblado de este fenómeno natural; como se puede inferir por el artículo publicado en el apartado de variedades titulado con el nombre Mejoras de la Ciudad, divulgado en el periódico el Ferrocarril. En el cual el ciudadano Morel ilustra algunas particularidades relacionadas con la construcción de la muralla (Calle 12 con carrera 4) para la defensa del camino del comercio, a cargo del señor Zamora, afirmando a su vez la necesidad de componer las calles de la ciudad, efectuada a finales de siglo:

(...) "El actual Gobernador del Departamento, con la buena voluntad que lo caracteriza, ha resuelto que la sección del Presidio que hoy trabaja en la muralla para la defensa del camino del Comercio, se dedique a una vez terminada esa obra, á la composición de nuestras calles. Y como vemos que muy pronto se dará término á esa importante mejora y por cierto de una manera muy satisfactoria y que honra mucho al señor Zamora, queremos hacer algunas observaciones que bien pueden servir para algo á nuestro probo y celoso Prefecto". Dijimos por ahi nuestras calles; en esto creemos estar equivocados. En Cali no hay calles. Hay algo así como playas por donde hubiera pasado una creciente dejando piedras de todos tamaños. En ocasiones se forman una especie de mares internos que mucho procupan a cierto 
amigo nuestro, porque teme que, con el tiempo, se nos suscite alguna cuestión internacional, como la del de Bhering. Pero lo más notable de todo son las cordilleras que dejan los que han abierto una cañería o desagüe. Como no pisan bien la tierra, procuran que el empedrado (léase desempedrado) quede levantado sobre el nivel de la calle, para que con el trascurso de los siglos, vuelva a su nivel natural. Creemos que el señor Director habrá observado esas alturas, desde las cuales se puede divisar, cuando la atmosfera lo permite, el Cabo de Hornos y a veces el de Buena Esperanza.

Esta última circunstancia es la que nos ha movido a escribir estas líneas, que a los que no hayan estado aquí parecerán exageradas. Pluguiera a Dios lo fueran.

Convencidos, pues, de que mientras haya que estar abriendo y cerrando desagües y cañerías, será inútil toda mejora que se haga, hemos creído que no sería inoportuno apuntar las obras previas necesarias y que son en nuestro concepto, las siguientes: Pilas de decantación en lo que llaman la toma. Estas pilas existieron hasta no sabemos qué año en que fueron cegadas porque se ahogó un hombre en una de ellas. Fue una fortuna que el desgraciado acontecimiento tuviera lugar allí y no en el rio, porque si a la fecha este hubiera desaparecido, según la lógica de la autoridad que en aquel entonces regia los destinos de esta noble y heroica ciudad de Santiago de Cali. Además de las pilas, sería conveniente el empleo de un paño filtro. Ignoramos cuánto costaría esté, pero creemos que no será mucho, y que todos contribuiríamos con gusto para la consecución de un objeto que nos daría salud y larga vida. En dias pasados se recogieron, en 24 horas, mil y tantos pesos para un baile, y ¿no sería posible obtener una suma tal vez inferior para algo más importante? No lo dudamos.

Una vez construidos el filtro y las pilas de decantación, debe la autoridad respectiva obligar a todos los que tengan agua a hacer sus cañerías y desagües (sobre todo estos últimos de cal y canto, si es que no se puede emplear tubería de fierro o siquiera de loza vidriada; pues el sistema actual de cañerías y desagües de piedras sueltas, además de tener las calles en el tristísimo estado en que hoy se encuentran, tienen el gravísimo inconveniente de privar a la población de agua potable que no sea la del rio. Esto lo exige la higiene, según opinión de personas competentes en la materia.

No debe admitirse la disculpa de falta de recursos, porque el que tiene agua tiene casa, y por consiguiente algo tiene. Igual observación debe hacerse respecto de los andenes. Son muy pocos los superiores a los empedrados de que hemos hablado. Todos ellos están construidos con un marcado declive hacia el centro de la calle, y así es que no hay tacón que no esté torcido e hígado que no esté enfermo. Por ahí por Santa Librada hay uno que merece exhibición. Hay otros entremezclados de ladrillo y cuadros de piedra menuda y construidos con tal arte que jamás logra uno pisar en el ladrillo sino en las piedrecillas aquellas, que es lo mismo que andar sobre espinas. Hay otros que mejor es no tocarlos.

Si el señor Director cree estas observaciones bien fundadas, le suplico se sirva darles cabida en su importante periódico.

Quedo del señor Director atento s.s., MOREL" (Morel 1893).

Siguiendo este orden de ideas, en cuanto a la fuerza del río Cali se encontró que una creciente ocurrida el 6 de noviembre de 1893, ocasionó un gran daño a una parte del dique que se estaba construyendo del puente para abajo hacia el vallano (El editor1893). Por consiguiente, se puede afirmar que el río Cali estuvo estrechamente ligado a la historia de la ciudad; en cuanto a las reglamentaciones para el uso público, protección del poblado y aprovechamiento en la agricultura y pesca.

\section{USO Y TRANSFORMACIONES}

Aunque la mayor característica distintiva del río fue su fuerte relación como elemento integrador de la comunidad, ofrecido por su ubicación central cercana al poblado; al permitir ser utilizado como un espacio lúdico y de recreación, gracias a que ofrecía grandes remansos a donde acudía las gentes a sus paseos con familiares y amigos; se puede afirmar que el río Cali debe su importancia a que su gran cauce abasteció el primer acueducto colonial que tuvieron los caleños. Estas construcciones utilizadas para la conducción del agua fueron las acequias; su principal uso fue el riego y el consumo doméstico. Su cuidado, uso y reparación estuvo a cargo de la administración local.

En el caso de la ciudad de Cali, la ruta escogida para la primera acequia, fue por la calle de la Merced que entraba a la ciudad y la conducía a lo largo de la carrera 4. Esta tenía diferentes usos entre los cuales se encuentran: el riego de huertas, el uso doméstico, el de apagar incendios y para el consumo después de haberse filtrado y guardado en tinajas de alfarería (Figura 1). El 24 de julio de 1547, el Cabildo decidió ofrecer el servicio de pajas de agua de la acequia entre los pobladores de la villa (Arboleda 1956). Ya para 1608, existirían 3 ramales en la carrera $4^{\mathrm{a}}$, una en la Mano del Negro y otra en la Carnicería.

En los autos de buen gobierno se observó la preocupación por el cuidado de la acequia, el 24 de diciembre de 1661 se le encargó a Alonzo Lozano el cuidado y la adecuación de la acequia (A.H.M.C. Tomo 6. Folio 49), en 1674 el 30 de junio, el alcalde Ordinario Juan Lasso de los Arcos ordenó un auto 
para que nadie rompiera alguna de las tres acequias (A.H.M.C. Tomo 7. Folio 146v).

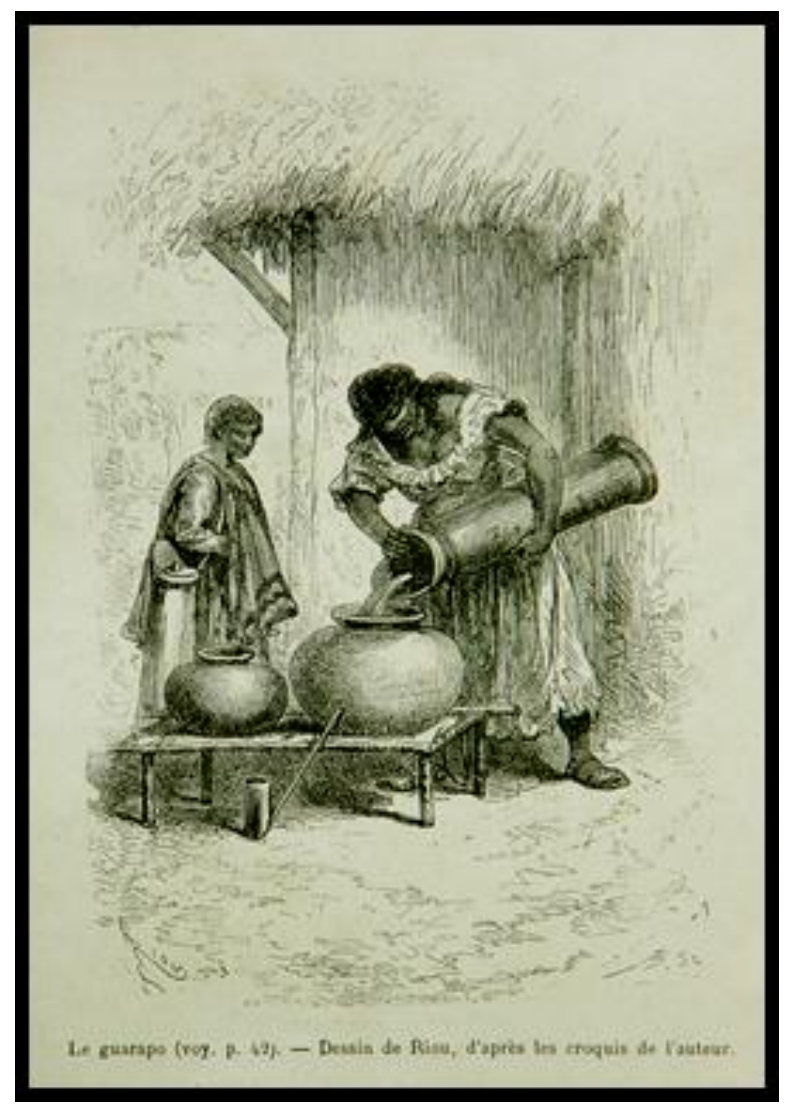

Figura 1. Tinajas para filtrar el agua. "El guarapo" tomado de (Edouard 1869).

Asimismo, a finales del siglo XVIII surgió un nuevo uso de la acequia: la Real Fábrica de Aguardiente; de la cual fue director Don Antonio Monzón. Esta fábrica se encontraba ubicada en la plaza principal y utilizaba el agua de la acequia principal para sus destilaciones, lo que a su vez permitía que fuese la encargada de su reparación y composición. La construcción en la que funcionaba la fábrica de Aguardiente era de piedra, cal y ladrillo, contaba con cuartos en los que se almacenaban las destilaciones de aguardiente, que según la opinión del Doctor Don Luis de Vergara correspondía al "más fuerte y mejor licor que se ve, en todo el Reyno, con el que se abastecen las administraciones subalternas de Popayan, Caloto, Quilichao, Buga, Cartago, Toro, Ancerma, Biga de Supia, provincia de Novita y Raposo" (A.H.M.C. Tomo34.Folio 156).

La mayor importancia de esta Real fábrica de Aguardiente, consistió en la renta comunal que dejaba a la administración local. Esta contaba con aproximadamente doce trabajadores entre los cuales estaban un contador, un fiel, un maestro, un sacador, dos oficiales, cinco peones, un cabo de ronda y otros subalternos vigilantes a los posibles fraudes.

Según los informes descriptivos de Don Antonio Monzón, director de la Fábrica de Aguardientes al Cabildo, sucesivos derrumbes se presentaban en el borde del Charco del Burro, los cuales resultaban bastante negativos tanto para el funcionamiento de la fábrica como para el aprovisionamiento del agua en la acequia principal de la ciudad. Un suceso bastante destacado ocurrió en Abril de 1795, en el que podemos apreciar lo siguiente:

\section{(...)"Don Antonio Monzon, Director de Real Fabrica del} Reyno, hace presente a V.S. que con motivo de alarma en esta ciudad a la reedificaciondeesta real fabrica de aguardiente en mas de cuatro años de he estado continuamente reparando la Azequia de las aguas a fin de que no falten en la fabrica para sus destilaciones, he notado los grandes derrumbes que ha havido en el Bogeo del Charco del Burro, y el inmiente riesgo en que por esta causa se alla esta real fabrica y toda la ciudad de que cayendo un derrumbe del Barranco que se alla ya deslizado, se lleve el poco talon que tiene la Azequia; y falte enteramente agua, sin que entonces quede arruinada para remediar con promtitud aquel daño: por esto, he practicado muchas diligencias, registrando todas las aguas que hey superiores; en este cerro de San Antonio y $[\text { sic }]^{2}$ y héallado que no son permanentes, y que solo se puede conducir la misma agua del rio, cogiendola en el sitio de Santa Rita, y pasandola por ensima del Bogeo de la Erradura: mas viendo que su costo seracresido por razon que hay que hacer quatro alcantarillas, romper muchas piedras grandes, hacer empartescañerias de calycanto;y traeria cubierta cubierta desde el Bojio hasta caja primera que esta enfrente de Flor Ramirez, desde donde se ha de aparar el agua para la ciudad, he [sic] y reconocido ser menos costo, y cubrirla de suerte que cuando vajen derrumbes de arriva, pasen al sin ofender la Azequia, y quitarle la por encima del Bogeo, para que no caigan Azequia, ni hagan canales en el cerro dandome la ciudad para este costo, pues tengo que hacer un Arco en el abra de la de San Antonio este la costea el Rey si el prejuicio que se le sigue de las muchas que bajan por esta loma a llenarlas cajas la cañeria y he experimentado que hora de una [sic] que hubo se cirven cajas y se nego parte de dicha carque (como les consta a los señores) de esta limpiando y habiendo en varias y resultando beneficio a esta ciudad de lo hago presente a V.S. para que se sirva determinar que [sic] por conbeniente para contar yo

${ }^{2}$ [sic]: expresión utilizada para advertir al lector sobre posibles errores en el texto que no fueron cometidos por quien cita el documento. En este caso la expresión se utiliza para advertir áreas del texto que no fueron legibles. 
Patiño (2012)

cuenta al señor director [sic] para la de [sic] caly" (A.H.M.C. Tomo 30.Folio 15-15v)

Ya para el año de 1813, la Real Fábrica estará extinta como lo afirma el síndico procurador Ignasio Ildefonso Núñez, al solicitar al Cabildo la reparación de la cañería por parte de este, a su vez proponiendo el cobro del servicio:

(...) "bien impuesto de que la cañeria de las aguas esta a venderse por que llenan las posetas de lodo y arena estorvaran su cauce; haviendoseestinguido la Real Fabricas de Aguardientes, que era la que reparaba sus daños, es los dispensable que V.S.M y se digno mandar que tomada razon por la escrivania de todos los sujetos, que mantienen en sus casas pajas de aguas paguen contandose la de el principio del año de 1810 hasta el presente, un cinco por ciento al año; con tal de que si quieren redimirse paguen la cantidad de cien patacones. Con este aucilio ya podran los propios de esta ciudad contan con un fondo alguno para su composicion; no faltaban las aguas que ahoras faltan en las acequias público, y concedido el permiso a todos los que quieran el agua en sus casas crecer este ramo para que los propios, como ya se ha visto, no tengan que faltar en esta compocicion con provecho de otros..." (A.H.M.C. Tomo 38. Folio 357-357v).

En la lista de contribuyentes para el pago del 5\% anual estaban las figuras más representativas de la nobleza y cabildantes de la ciudad; entre los cuales figuran: El Doctor Don Joaquín de Cayzedo, El Señor Don José María Mallarino, El Señor Procurador General Doctor Don Ignacio Nuñes, Don Jose Borrero, Don Nicolas Silva, El Señor Regidor Don Martin Guerrero, El Señor Administrador Don Juan Antonio Dorronsoro, Don Bernardo Valens, los herederos del Cura Vicario Doctor Don Juan Ignacio Montalvo, Doña Lusia De La Flor, El Señor Regidor Don Domingo Montoya, Los herederos De Doña Antonia De Castro y El Señor Don Juaquin Micolta (A.H.M.C. Tomo 38. Folio 366).

En relación con la distribución de pago por pajas de aguas; se puede afirmar que la utilización y la preocupación por establecer leyes en beneficio para el cuidado de la acequia, correspondió a los primeros intentos por construir un sistema de acueducto para la ciudad; que garantizara el abastecimiento de agua a la población, privilegiando a los usuarios de mayor abolengo y prestancia socioeconómica.

Para el año de 1824, el maestro de alfarería Don José Nicolás de Silva, presentó un informe de la comisión para el reparo de la cañería pública, la cual continuamente se veía afectada por las crecientes del río, en el cual informa que:

\section{Uso histórico del agua en Cali}

(...) "se me comisiono para la composicion de las aguas de la cañeria publica, a tiempo que por una creciente del rio, se sego enteramente, demodo que tuve necesario trabajar tanto, y gastar muchos dias, con un crecido numero de peones, hasta dejarla corriendo y limpias todas las posetas que del mismo modo se hallavan repletas y tan apretada la arena, que fue necesario executarlo con Yanas. Ygualmente se hicieron unos paredones de piedras muy grandes para evitar el trancito de a caballo, por encima del charco que llaman del burro, pues actualmente se echava a perder la cañeria con aquel [sic] tivo....Sala consistorial de cali abril 19 de 1824" (A.H.M.C. Tomo 38.Folio 366).

El crecimiento demográfico de la población provocó que el Cabildo ordenara la creación de otros sistemas de consumo para el bien común de las personas menos favorecidas; quienes carecían de agua limpia y tomaban el agua directamente del cauce del río. Se optó entonces por la colocación de pilas en los demás barrios del cantón entre las cuales se destacan las pilas de San Nicolás y San Francisco por haber sido los barrios más lejanos de la plaza con un nivel de crecimiento demográfico más alto; igualmente, todas las obras públicas de la ciudad fueron construidas con la suscripción voluntaria por no existir fondos de las rentas municipales, fechado el 11 de junio de 1836.

Así mismo, continuaron a largo del siglo, las refacciones en la cañería, producto de las crecidas del río, como bien lo expresa el Jefe Municipal Leandro Canaba el 1 de diciembre de 1843 al afirmar que el acueducto público de la ciudad sufría muchos arreglos por causa de la naturaleza del terreno $y$ a las malas construcciones realizadas anteriormente; presentándose una situación que disminuía los dineros de las rentas municipales, que a su vez provocaba el aumento en la contribución económica de los propietarios de pajas de aguas, al ser estas las que más necesitaban atención. Se expresaba que:

(...) "Para minorar este mal, creé la gefatura que se debe aumentar la contribucion de los que llevan a las casas pajas de agua, porque generalmente son estas cañerias las que exigen los reparos y composiciones que semanalmente se hacen. A primera vista, parece monstruoso el proposito: mas lejos de ser así, sucede todo lo contrario, pues en la economia y arreglos domesticos, estriba el bien estarde las familias, vosotros mismos conoceis muy delculto, los abusos que reinan siempre en el ramo de criados, en aquellas familias, a quienes la necesidad obliga a proveerse de agua; acarriandola del rio.

¿pensais que no comprarian gustosas, la libertad de estos malos ratos, por la insignificante cantidad de siete o dies pesos? ¿Y pensaraís, que por esta misma, no querran los que ya tienen el agua en las casas, continuar gozando de 
este beneficio, sin tener a cada paso que atender a la reparacion de sus cañerias, que si hara siempre por el fontanero publico?

En cuanto á la dístribucíon delas pajas de agua, ella se vé hoy lo mas arreglado posible; sin embargo, existe un abuso que debeis esforzaros en remover. Este es, el que algunas personas en asocio privado, sacan el permiso para poner el agua en sus respectivas casas, partiendo entre si la paja; esta compañia que solo existe entre ellas, sin que las rentas puedan recaudar de ambas el derecho es el germen de continuas discordias entre ellasque vienen siempre a pasar en quejas y reclamos ante los jefes de policia. Tomad este incidente en consideracion, y obrareís un gran bien" (A.H.M.C. Tomo 56. Folio 179v-180).

De acuerdo al relato de Isaac Holton, se infiere que para 1849 el sistema del acueducto principal de la ciudad de Santiago de Cali era más grande que el acueducto de la ciudad de Bogotá. El acueducto de Cali, estaba constituido por el sistema de la acequia principal de la carrera cuarta y la distribución de sus ramales. Según Holton (1857), la acequia bajaba por el margen derecho del río Cali por encima de una cañada. Afirmaba que las dimensiones externas eran de aproximadamente 30 pulgadas cuadradas y describía que dicha acequia se encontraba completamente destapada o a la intemperie al bajar el río" (Holton1857).

Aun así, con todas las medidas de reparación y la falta de presupuesto municipal para el 1 de abril de 1855, el Jefe Municipal Vicente Ochoa informó al Consejo Municipal de la urgencia de arreglar el acueducto público, debido a que ya para esta fecha se prestaba el servicio en la ciudad del suministro de 75 pajas particulares, cuatro pilas públicas, y las pajas del edificio de San Francisco, Santa Librada, el Hospital San Juan de Dios y La Merced, al igual que las acequias que corrían libremente en la ciudad para el consumo de la población pobre. A su vez manifestaba, su preocupación por los daños y suciedad que se presentaban en el agua de consumo doméstico provocado por los derrumbes en los bordes del Río Cali (A.H.M.C. Tomo56. Folio 346-346v).

De la misma forma, para 1893, el periódico El Ferrocarril publicó una descripción del sistema de cañerías y desagües de la ciudad, los cuales para finales de siglo, estaban construidos en piedra suelta lo que conllevaba al daño de las calles y a la contaminación del agua en las acequias, provocando que sólo fuese consumible el agua directamente del río en su naciente (Anónimo 1893).

A mitad del siglo XX, existía aún la acequia principal de la carrera cuarta utilizada como acueducto colonial en la ciudad; la cual en un tramo conducía el agua por una mampostería construida en piedra seca y con calicanto (cal, arena y baba de tuna). Tomando el agua del río Cali, al occidente de la Hacienda Santa Rosa, avanzaba bordeando la pendiente que caía al río para formar "el Charco del Burro" (Vásquez 2001). No obstante, el sistema de alcantarillado no existía y durante todo el siglo XIX se utilizó y toleró el uso de acequias superficiales para el desagüe de las aguas negras y usadas, cubiertas con piedra de cantera de escasa profundidad que se vertían posteriormente a las llanuras de la ciudad.

En la siguiente imagen de mediados del siglo XIX (Figura 2), se puede observar el sistema de conducción de agua por medio de la acequia principal, la cual recorría toda la carrera cuarta. Se aprecian claramente las malas condiciones en cuanto al uso del agua, al encontrarse ésta a la intemperie.

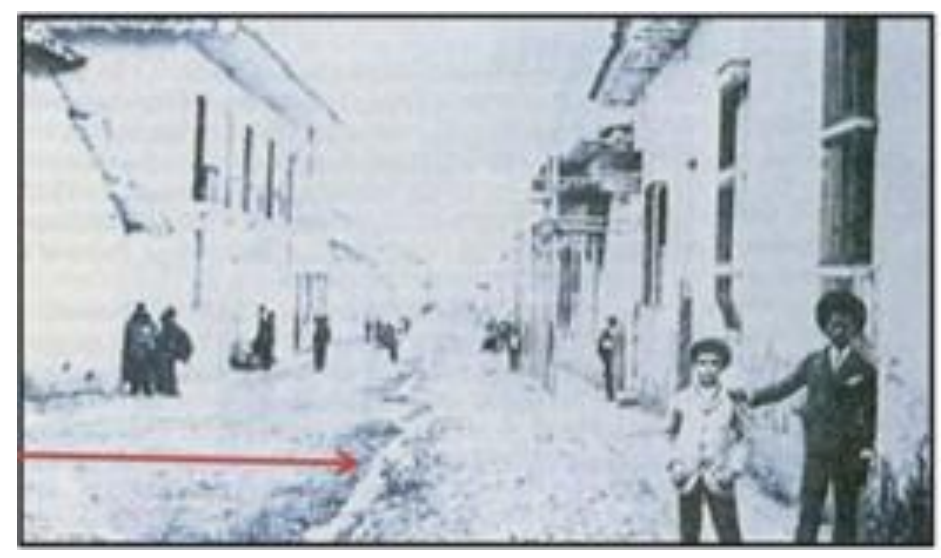

Figura 2. Acequia Principal. Calle Cuarta a mediados del siglo pasado. Tomado de (Castro 1957).

\section{CONCLUSIONES}

Este estudio de caso evidencia como el uso del recurso hídrico para la población estuvo delimitado en cuanto a los parámetros de estratificación social (pajas de agua para el Ilustre Consejo Municipal), en la necesidad delos lugares (hospitales-colegio-conventos) y gente del común (pilas públicas).

La importancia del río Cali radicó durante los periodos estudiados, en una forma de control de puntos estratégicos sobre el cauce en beneficio de la población en crecimiento; a fin de controlar los cambios en el caudal. Así mismo, el río fue un afluente social estructurante como foco unificador de la sociedad, al concebirse como un lugar de recreo, lúdico y laboral. 
Patiño (2012)

La historia del agua en la ciudad de Cali amerita una continuidad en el estudio del proceso de expansión y detrimento de humedales y ríos, vistos durante la expansión urbana de mitad del siglo $\mathrm{XX}$ bajo un discurso higienista expansista.

\section{AGRADECIMIENTOS}

El presente manuscrito fue posible gracias al proyecto urbanístico del Hundimiento de la Avenida Colombia, financiado por el Instituto para la Investigación y la Preservación del Patrimonio Cultural y Natural del Valle del Cauca-INCIVA.

\section{REFERENCIAS}

A.H.M.C. Archivo Histórico Municipal de Cali. Tomo 6.

A.H.M.C. Archivo Histórico Municipal de Cali. Tomo 7.

A.H.M.C. Archivo Histórico Municipal de Cali. Tomo 14.

A.H.M.C. Archivo Histórico Municipal de Cali. Tomo 15.

A.H.M.C. Archivo Histórico Municipal de Cali. Tomo 17.

A.H.M.C. Archivo Histórico Municipal de Cali. Tomo 30.

A.H.M.C. Archivo Histórico Municipal de Cali. Tomo34.

A.H.M.C. Archivo Histórico Municipal de Cali. Tomo 38.

A.H.M.C. Archivo Histórico Municipal de Cali. Tomo 43.

A.H.M.C. Archivo Histórico Municipal de Cali. Tomo 47.

A.H.M.C. Archivo Histórico Municipal de Cali. Tomo 56.

A.H.M.C. Archivo Histórico Municipal de Cali. Tomo 61.

ANÓNIMO. 1893. Descuido Criminal. El Ferrocarril (6 de octubre).

ARBOLEDA, G. 1956a. Historia de Cali. Cali: Universidad del Valle, Tomo I.

ARBOLEDA, G. 1956b. Historia de Cali: Universidad del Valle Tomo II.

ARBOLEDA, G. 1956c. Historia de Cali: Universidad del Valle Tomo III.

\section{Uso histórico del agua en Cali}

CASTRO, B. 1957. El caudillo radical David Peña: protagonista de una cruenta toma de Cali en 1876. Política y diplomacia en la historia de Colombia: Credencial Historia 9. [Consultado 25 de mayo de 2012].Disponible en línea:

http://www.banrepcultural.org/blaavirtual/revistas/crede ncial/septiembre1990/septiembre2.htm

EDOUARD, A. 1869. L’Amerique Equinoxiale (ColombieEquateur-Perou). Librería Hachette, Paris.

EL EDITOR. 1893. El río. El Ferrocarril (10 de noviembre).

HOLTON, I. 1857. La nueva granada: Veinte meses en los Andes. Traducción Ángela de López: Publicado en inglés. Harper and Brothers, New York.

MOREL. 1893. Mejoras de la Ciudad. El Ferrocarril (29 de septiembre).

PALACIOS, E. 1886. El Alférez Real. Ediciones Universales, Bogotá.

VÁSQUEZ, E. 2001. Historia de Cali en el siglo XX. Artes gráficas del Valle, Cali. 